\title{
Identifying efficient dairy heifer producers using production costs and data envelopment analysis ${ }^{1}$
}

\author{
A. J. Heinrichs, ${ }^{* 2}$ C. M. Jones, ${ }^{*}$ S. M. Gray, ${ }^{* 3}$ P. A. Heinrichs, ${ }^{\star}$ S. A. Cornelisse, $\dagger$ and R. C. Goodling \\ *Department of Animal Science, and \\ †Department of Agricultural Economics, Sociology, and Education, The Pennsylvania State University, University Park 16802
}

\begin{abstract}
During November and December 2011, data were collected from 44 dairy operations in 13 Pennsylvania counties. Researchers visited each farm to collect information regarding management practices and feeding, and costs for labor, health, bedding, and reproduction for replacement heifers from birth until first calving. Costs per heifer were broken up into 4 time periods: birth until weaning, weaning until 6 mo of age, 6 mo of age until breeding age, and heifers from breeding to calving. Milk production records for each herd were obtained from Dairy Herd Improvement. The average number of milking cows on farms in this study was $197.8 \pm 280.1$, with a range from 38 to 1,708 . Total cost averaged $\$ 1,808.23 \pm \$ 338.62$ from birth until freshening. Raising calves from birth to weaning cost $\$ 217.49$ \pm 86.21 ; raising heifers from weaning age through 6 mo of age cost $\$ 247.38 \pm 78.89$; raising heifers from 6 mo of age until breeding cost $\$ 607.02 \pm 192.28$; and total cost for bred heifers was $\$ 736.33 \pm 162.86$. Feed costs were the largest component of the cost to raise heifers from birth to calving, accounting for nearly $73 \%$ of the total. Data envelopment analysis determined that 9 of the 44 farms had no inefficiencies in inputs or outputs. These farms best combined feed and labor investments, spending, on average, $\$ 1,137.40$ and $\$ 140.62 /$ heifer for feed and labor. These heifers calved at $23.7 \mathrm{mo}$ of age and produced $88.42 \%$ of the milk produced by older cows. In contrast, the 35 inefficient farms spent $\$ 227$ more on feed and $\$ 78$ more on labor per heifer for animals that calved 1.6 mo later and produced only $82 \%$ of the milk made by their mature herdmates. Efficiency was attained by herds with the lowest input costs, but herds with higher input costs were also able to be ef-
\end{abstract}

\footnotetext{
Received December 15, 2012.

Accepted August 2, 2013.

${ }^{1}$ This research is a component of NC-1042; Management Systems to Improve the Economic and Environmental Sustainability of Dairy Enterprises.

${ }^{2}$ Corresponding author: ajh@psu.edu

${ }^{3}$ Current address: Department of Pharmacology, University of Virginia, Charlottesville, VA 24430.
}

ficient if age at calving was low and milk production was high for heifers compared with the rest of the herd. Key words: heifer, economics, cost of production, data envelopment analysis

\section{INTRODUCTION}

Dairy heifers are the future revenue-generating units on a dairy operation. However, during their pre-productive period, they represent a significant cost center. It has been shown that the total cost of raising dairy heifers is the second largest contributor to the annual operating expense of dairy farms in Pennsylvania (Tozer and Heinrichs, 2001). A study of livestock and crop enterprises on 8 Michigan dairy farms found that heifer costs were the third largest expense to the dairy and comprised $12.5 \%$ of total costs in 1998 (Harsh et al., 2001). In New York surveys, costs of raising dairy heifers have been shown to represent 15 to $20 \%$ of total annual expenses of a dairy farm (Karszes, 1994). However, because the annual expenses of raising heifers are included in various other broad expense categories such as feed, labor, and health, most dairy farms do not routinely calculate the actual cost of raising a replacement animal or track heifer rearing as an enterprise. Furthermore, many operations fail to realize that management and care of dairy heifers throughout this pre-productive period directly influence productivity and incomegenerating potential of these animals during their first and subsequent lactations. Daily management decisions relating to an operation's heifers can compound to have a great effect on current and future farm profitability in the form of hidden expenses and lost productivity (Zanton and Heinrichs, 2005).

Benchmarks are available for producers to use in setting appropriate production goals. Milk production in first lactation was optimized when ADG before puberty was $800 \mathrm{~g} / \mathrm{d}$ in a meta-analysis (Zanton and Heinrichs, 2005). Recommended BW for heifers is $85 \%$ of mature BW after calving (NRC, 2001), and age at first calving (AFC) of 23 to 24 mo is recommended for an optimum balance between rearing costs and milk production (Heinrichs, 1993). Peak milk production 
of first-lactation animals that is 75 to $80 \%$ of mature herdmates is considered a goal for smooth transition into the lactating herd (Nordlund and Cook, 2004).

Benchmarking production relative to other operations can be misleading because of the large number of factors that affect heifer performance and costs, as well as the complex interactions between inputs. In addition, benchmarking compares an individual farm to the average farm in the peer group rather than identifying optimum levels of input or performance for the individual herd. Data envelopment analysis (DEA; Cooper et al., 2000) is a nonparametric method of calculating the efficiency of individual decision-making units (DMU), such as a dairy farm or the heifer enterprise of that farm, that can be used to analyze performance of the enterprise and assist managers in determining the best combination of inputs that results in efficient production. The nonparametric nature of this methodology enables the analyst to avoid having to make assumptions about the distribution of the data. Multiple input and output variables can be analyzed simultaneously to account for interactions affecting efficiency. This type of analysis has been used to identify which efficient dairy producers make up the frontier of the production possibility set and to develop custom benchmarks for each operation that consider the available inputs rather than simply targeting the highest level of milk production (Stokes et al., 2007).

The goal of this project was to determine the actual costs to raise dairy heifers in late 2011 in Pennsylvania by surveying dairy producers and to identify, through DEA, the farms most efficiently using (major) inputs to produce potentially profitable dairy heifers in Pennsylvania, combining factors that enhance efficiency in production and business management. Because the dairy heifer enterprise represents one of the largest economic components to the production of milk, the outcomes of this study should provide valuable information that Pennsylvania dairy farms can implement to improve their competitive position and remain sustainable in the future.

\section{MATERIALS AND METHODS}

During November and December 2011, data were collected from 44 dairy operations in 13 Pennsylvania counties that represented a wide cross-section of herd sizes and management types. Farms were selected as a convenience population through contact with extension educators in 4 primary dairy areas of Pennsylvania, with the requirement that they were DHI participants to ensure access to milk production records. Researchers visited each farm to conduct an oral survey, which consisted of collecting information regarding manage- ment practices and costs incurred for feeding, labor, health, bedding, and reproduction for replacement heifers from birth until first calving. The data collection interview required approximately $2 \mathrm{~h}$ for each farm and was conducted with the farm owner or manager. If other people on the farm were responsible for feeding calves and heifers or for purchasing feed, those people were also interviewed to collect complete information.

Costs for heifers were divided into 4 time periods to align with stages of heifer development: birth until weaning, weaning until 6 mo of age, 6 mo of age until breeding age, and bred heifers (heifers from breeding to calving) using an established model (Gabler et al., $2000,2007)$. Values of animals were estimated from local auction prices for the period of the study. Newborn heifer calves were valued at $\$ 160$, heifers between weaning and 6 mo of age were $\$ 600$, and heifers between 6 mo and breeding age were $\$ 700$. Once bred, heifers were valued at $\$ 1,400$. These values were used to estimate interest and mortality costs only. Gestation length was set at $289 \mathrm{~d}$ for bull-bred animals. Using DHI records, AFC was calculated for heifers that calved in calendar year 2011 for each farm. Costs were reported on a perheifer basis. If actual forage or bedding costs were not provided by the producer, fair market price from that period was used. Market prices were drawn from the October 2011 feed price list assembled by the Department of Animal Science at Penn State (Ishler, 2011). If calves were fed milk replacer, costs were calculated based on producer-reported costs. For calves fed milk, the cost of nonpasteurized waste milk was estimated at $\$ 0.032 / \mathrm{kg}(\$ 6.98 / \mathrm{cwt})$ and saleable milk was calculated at $\$ 0.10 / \mathrm{kg}(\$ 22.15 / \mathrm{cwt})$. When calves received a mix of waste and saleable milk, the cost was averaged to $\$ 0.066 / \mathrm{kg}$ (\$14.57/cwt). Milk costs were determined from regional averages from 2011 (USDA, 2011a). Pasture costs were estimated at $\$ 0.70 / \mathrm{d}$ per head based on average forage production and value obtained from the Pennsylvania Agricultural Statistics Service (USDA, 2012). Labor costs were estimated with an hourly wage of $\$ 11$ per laborer, regardless of whether laborers were family members or hired employees (USDA, 2011b). If producers were unable to estimate the cost of vaccinations and deworming treatments, a fair market price was assigned by averaging internet price quotes obtained in November 2011. If producers reported an incidence of scours, that percentage was used in calculating costs on a per-animal basis. If no incidence of scours was reported, incidence was fixed at $25 \%$ and treatment costs were estimated (USDA, 2007). Mortality costs were calculated using mortality rates from the National Animal Health Monitoring System Dairy 2007 survey (USDA, 2007). Average mortality for heifers was therefore set at $7.8 \%$ before weaning and $1.8 \%$ for older 
heifers. The $1.8 \%$ mortality rate for weaned heifers was divided evenly for the 3 stages of weaned heifers (weaning to $6 \mathrm{mo}$ of age, $6 \mathrm{mo}$ of age to breeding, and bred heifers) for a $0.6 \%$ mortality rate at each stage. Interest costs were estimated with an interest rate of $2 \%$, which was assumed as an approximate rate of return for an alternative short-term investment. For each stage of life, costs for that stage were incorporated to calculate interest costs. Manure removal, building depreciation, and equipment usage specifically for heifers were not determined because assigning accurate values proved difficult.

On each farm, a subsample of 3 to 5 weaned calves, breeding-age heifers, and prefresh heifers were measured for age, weight, and height. Heifer weight was estimated using a standard dairy cow weight tape (Heinrichs et al., 1992). These data were used to reflect relative size of heifers at various ages.

Costs are reported for feed, labor, bedding, health, reproduction, interest, and mortality for 4 life stages of the replacement heifer. Production data, including AFC, peak milk, peak DIM, projected 305-d actual milk, projected 305-d actual protein, and projected 305-d actual fat, were collected from individual farms using 2011 DHI records. Correlations were calculated on economic, management, and production data to determine possible causal effects and to help in interpreting data. Statistical significance was declared at $P$ $<0.05$ and trends at $P<0.10$.

Whole-farm efficiency was measured via DEA using software developed by Cooper et al. (2000) and replicated using the benchmark package in $\mathrm{R}$ (Bogetoft and Otto, 2013; R Development Core Team, 2013). Conducting DEA is a nonparametric method of calculating efficiency of individual farms to measure various performance outcomes and benchmarks (Stokes et al., 2007). The DEA model used was a BCC (Banker et al., 1984) input-oriented, variable returns-to-scale (VRS) model. This method defines a production possibility set based on the attributes of the most efficient DMU and their convex hull. Input-oriented models seek to reduce inputs to the lowest levels possible while still producing at least the present level of output. Input variables used were feed and labor costs and output variables were AFC and the average first-lactation milk production of heifers as a percentage of the average production of all other cows in the herd. The input-oriented VRS model was used because a dairy farm ideally strives to minimize cost of production. A VRS model was chosen because of the dynamic nature of animal and farm production, because we have farms of various sizes where economics and diseconomies of size would be expected. Age at first calving was transformed $(30$ - observed $\mathrm{AFC}$ ) for the DEA model, so lower AFC was considered more desirable to avoid operations with higher AFC being considered more efficient. Back-transformed values for AFC are presented to facilitate interpretation of the results.

Bootstrap efficiency scores, as introduced by Simar and Wilson (1998), were determined using the benchmarking $\mathrm{R}$ package (Bogetoft and Otto, 2013). A bootstrap DEA is used to account for some of the bias that is likely in DEA efficiency scores when finding a "true" efficiency frontier. This method provides a biascorrected efficiency score and confidence interval $(\alpha=$ $0.05)$ for the "true" efficiency score for each DMU. This procedure corrects for bias by approximating the distribution of the difference between the true and estimated efficiency scores and creates an estimation of the bias and confidence intervals for each DMU.

\section{RESULTS AND DISCUSSION}

Average number of milking cows on farms in this study was $197.8 \pm 280.1$ (results are mean \pm SD unless otherwise specified), with a range of 38 to 1,708 . Table 1 provides averages of heifer performance for the herds in this study. Estimates of total costs and costs by growth stage for raising a replacement heifer are listed in Table 2. Total cost averaged $\$ 1,808.23 \pm \$ 338.62$ from birth until freshening. Raising calves from birth to weaning cost $\$ 217.49 \pm 86.21$; from weaning age through 6 mo of age, the cost was $\$ 247.38 \pm 78.89$; from 6 mo of age until breeding, the cost was $\$ 607.02 \pm 192.28$; and the total cost for bred heifers was $\$ 736.33 \pm 162.86$. This average is substantially higher than costs published in previous studies (Karszes, 1994; Gabler et al., 2000) and primarily reflects changes in market conditions for feeds since the time of those studies. These results are more similar to those from a 2007 survey of 49 Wisconsin dairy farms and custom calf and heifer operations, which indicated that the cost of raising dairy heifers from birth to freshening ranged from $\$ 1,595$ to $\$ 2,935$ (Zwald et al., 2007). This was a $58 \%$ increase compared with an earlier Wisconsin survey (Hoffman et al., 1999). Total costs for each period were correlated both with total costs for all other periods and total overall costs $(P<0.01)$, as would be expected. In addition, total costs showed a trend for correlating with age prefreshening $(\mathrm{r}=0.27, P=0.08)$ as well as a correlation with weight $(\mathrm{r}=0.44, P<0.01)$ and height $(\mathrm{r}=0.54$, $P<0.01$ ) of measured prefresh heifers. Heifers calving at older ages were more costly but were larger in size at calving. Total cost for bred heifers was negatively correlated with age of prefresh heifers $(\mathrm{r}=-0.30, P<0.01)$ and positively correlated with weight of prefresh heifers $(\mathrm{r}=0.32, P=0.04)$ as well as daily cost between $6 \mathrm{mo}$ of age and breeding $(\mathrm{r}=0.68, P<0.01)$. Overall total 
Table 1. Description of herd size and heifer performance on the 44 Pennsylvania farms studied

\begin{tabular}{lcccc}
\hline Item & Mean & SD & Minimum & Maximum \\
\hline No. of cows in herd & 198 & 280 & 38 & 1,708 \\
Weaning age, d & 57 & 17 & 32 & 110 \\
Age at first service, d & 444 & 73 & 337 & 697 \\
Age at calving, mo & 25.0 & 1.7 & 22.2 & 29.0 \\
Average age of prefresh heifers, ${ }^{1} \mathrm{~d}$ & 776 & 73 & 638 & 1,023 \\
Average weight of prefresh heifers, ${ }^{1} \mathrm{~kg}$ & 573.18 & 46.60 & 473.21 & 714.86 \\
Average height of prefresh heifers, ${ }^{1} \mathrm{~cm}$ & 140.18 & 4.34 & 133.99 & 152.40 \\
Peak milk, ${ }^{2} \%$ of herdmates & 75.33 & 4.85 & 62.47 & 89.08 \\
Projected 305-d actual milk, ${ }^{2} \%$ of herdmates & 83.32 & 6.19 & 66.58 & 99.31 \\
${ }^{1}$ Based on a sample of 3 to 5 heifers per farm. \\
${ }^{2}$ Calculated from DHI records; production of first-lactation heifers as a percentage of production of all other \\
cows in the herd.
\end{tabular}

costs were correlated with prefresh weight $(\mathrm{r}=0.49, P$ $<0.01)$ and height $(\mathrm{r}=0.54, P<0.01)$. Overall total costs were also strongly correlated with number of days between 6 mo and breeding, as would be expected $(\mathrm{r}=$
$0.31, P=0.04)$, and daily cost between 6 mo of age and breeding $(\mathrm{r}=0.87, P<0.01)$.

Feed costs for all age groups are reported in Table 2 and comprised roughly $73 \%$ of total costs. This is

Table 2. Heifer rearing costs by stage and overall for the 44 Pennsylvania farms studied (cost data collected in November and December 2011)

\begin{tabular}{|c|c|c|c|c|}
\hline Item & Mean & $\mathrm{SD}$ & Minimum & Maximum \\
\hline \multicolumn{5}{|l|}{ Birth to weaning, $\$$ / heifer } \\
\hline Feed & 124.95 & 56.43 & 29.06 & 259.17 \\
\hline Labor & 58.59 & 36.63 & 12.63 & 154.00 \\
\hline Bedding & 11.97 & 14.51 & 0.00 & 74.70 \\
\hline Health & 6.25 & 6.24 & 0.18 & 21.44 \\
\hline Total for this period & 217.49 & 86.21 & 89.41 & 442.78 \\
\hline \multicolumn{5}{|l|}{ Weaning to $6 \mathrm{mo}, \$$ /heifer } \\
\hline Feed & 171.82 & 54.26 & 71.45 & 302.44 \\
\hline Labor & 34.30 & 24.10 & 6.05 & 123.14 \\
\hline Bedding & 20.43 & 27.74 & 0.00 & 153.75 \\
\hline Health & 2.45 & 2.93 & 0.00 & 14.14 \\
\hline Total for this period & 247.38 & 78.89 & 109.75 & 510.17 \\
\hline \multicolumn{5}{|l|}{6 mo to breeding, $\$ /$ heifer } \\
\hline Feed & 474.88 & 163.65 & 213.64 & 941.02 \\
\hline Labor & 56.92 & 36.24 & 10.13 & 152.43 \\
\hline Reproduction & 49.26 & 22.46 & 13.34 & 122.36 \\
\hline Bedding & 32.66 & 38.92 & 0.00 & 198.00 \\
\hline Health & 4.10 & 4.57 & 0.00 & 24.96 \\
\hline Total for this period & 607.02 & 192.28 & 286.85 & $1,112.56$ \\
\hline \multicolumn{5}{|l|}{ Breeding to freshening, $\$ /$ heifer } \\
\hline Feed & 546.20 & 159.66 & 290.25 & 961.25 \\
\hline Labor & 52.70 & 32.01 & 7.87 & 126.44 \\
\hline Bedding & 25.05 & 37.94 & 0.00 & 158.95 \\
\hline Health & 4.55 & 5.76 & 0.00 & 25.42 \\
\hline Total for this period & 736.33 & 162.86 & 430.65 & $1,127.20$ \\
\hline \multicolumn{5}{|l|}{ Birth to freshening, $\$$ / heifer } \\
\hline Feed & $1,317.86$ & 281.18 & 819.12 & $1,979.85$ \\
\hline Labor & 202.51 & 98.90 & 66.25 & 435.98 \\
\hline Bedding & 90.11 & 80.50 & 0.00 & 391.83 \\
\hline Reproduction & 49.26 & 22.46 & 13.34 & 122.36 \\
\hline Health & 17.34 & 12.98 & 2.89 & 66.25 \\
\hline Total cost of rearing & $1,808.23$ & 338.62 & $1,128.50$ & $2,504.75$ \\
\hline \multicolumn{5}{|l|}{ Daily feed cost, $\$ /$ heifer } \\
\hline Birth to weaning & 2.17 & 0.80 & 0.91 & 3.81 \\
\hline Weaning to $6 \mathrm{mo}$ & 1.39 & 0.40 & 0.60 & 2.40 \\
\hline 6 mo to breeding & 1.67 & 0.47 & 0.75 & 2.71 \\
\hline Breeding to freshening & 1.89 & 0.55 & 1.00 & 3.33 \\
\hline Birth to freshening & 1.73 & 0.36 & 1.09 & 2.70 \\
\hline Total daily cost, birth to freshening, $\$$ / heifer & 2.38 & 0.41 & 1.50 & 3.24 \\
\hline
\end{tabular}


higher than in previous studies because of the large increase in feed costs in recent years compared with other input costs. In addition, the current study does not include depreciation and manure costs that may have been included in previous studies. Cost data from Wisconsin found that labor and management $(47 \%)$ and feed $(34 \%)$ were the highest costs for the calf enterprise to $9 \mathrm{wk}$ of age and that observed feed costs accounted for $51 \%$ or more of the heifer enterprise expenses. In the present study, feed costs from birth to weaning were correlated with labor costs during this stage $(\mathrm{r}=0.42$, $P<0.01$ ), as would be expected, because milk feeding is typically labor intensive. Farms that spent more on feeding also tended to spend more on overall health costs $(P=0.02)$ and overall labor $\operatorname{costs}(P=0.02)$. Total feed costs were correlated with weight $(\mathrm{r}=0.34$, $P=0.03)$ and height $(\mathrm{r}=0.43, P<0.01)$ in measured prefresh heifers. Average daily feed costs are shown in Table 2 and reflect the large variation observed in feeds offered and used on the farms. Although we did not include capital costs in this analysis, the type of housing used for rearing heifers could influence feed, and especially, labor costs. Pasture access for bred heifers was used to varying degrees by 29 farms, whereas the remaining 15 offered no access to pasture. Because feed costs for bred heifers represent a large portion of total costs, pasture allowance affected overall costs of raising heifers in some cases. Bedding costs ranged greatly as some farms used a minimal amount whereas others used a lot; in all cases, bedding was quite expensive and often added significant cost.

Total costs to raise heifers have increased substantially in the past $10 \mathrm{yr}$, and the feed cost component has also increased, from 60 to $64 \%$ of total costs in 1999 (Gabler et al., 2000) to almost 73\% in the current study. Rearing costs for all age groups increased, with the largest percentage increase in preweaned calves, largely due to feed costs but also due to labor.

Inputs for the DEA model are shown in Table 3, and the results are shown in Table 4 . Nine of the 44 DMU (i.e., farms) were identified as being efficient according to the BCC VRS model, having a radial efficiency score equal to 1 , as well as no input or output slacks. These farms best combined feed and labor investments to produce heifers with low AFC and high first-lactation milk production. These efficient farms spent, on average, $\$ 1,137.40$ and $\$ 140.62 /$ heifer for feed and labor on heifers that calved at 23.7 mo of age and produced $88.42 \%$ of the milk produced by older cows. By contrast, the 35 DEA inefficient farms spent $\$ 226.87$ more on feed and $\$ 77.81$ more on labor per heifer for animals that calved 1.6 mo later than those on efficient farms and produced only $82.01 \%$ of the milk made by their mature herdmates.
A DEA efficiency score of 1 means that a farm is efficiently using the inputs at their given levels to produce the given output levels. On the other hand, an efficiency score of 0.95 indicates that the farm should be able to produce the given outputs with $95 \%$ of the inputs used. Input and output slacks are interpreted as hard units of the amount by which an input is overused or by which an output is underproduced beyond the efficiency score. For inefficient farms, where no slack is presented, no additional input decrease or output increase is required. For example, DMU 5 had an efficiency score of 0.750 , indicating that the farm should be able to produce its outputs with $75 \%$ of the input levels used. To become efficient, the farm would need to decrease its use of both inputs by $1-0.750=0.250$, or $25 \%$. At the same time, the farm should also decrease labor costs by $\$ 82.13$, decrease AFC by $0.1 \mathrm{mo}$, and increase milk production of heifers relative to the rest of the herd by 5.19 percentage points.

The substantial lack of slack values for feed cost indicates that this input was generally not a factor affecting efficiency on the farms in this study. Labor costs were shown to have a greater effect on efficiency, with inefficient farms spending around $\$ 56 /$ head more on labor than efficient farms, ranging from $\$ 0.46$ to $\$ 166.21$. Among the inefficient herds, slack values for AFC ranged from 0.1 to $4.8 \mathrm{mo}$, and slacks for milk production of heifers compared with the rest of the herd ranged from 0.65 to $21.4 \%$.

One of the advantages of DEA is that it identifies benchmarks for performance of farms included in the study. The DEA model identifies appropriate efficient DMU for each inefficient DMU for comparison. In some cases, the benchmark DMU is a single operation, but in other cases, the model identifies and weights multiple DMU to be used in benchmarking performance; the difference between the weighted combination of benchmark DMU and the DMU in question is the source of slack values described above. As an example, for DMU 5 , the model-determined benchmark DMU was DMU 21 (Table 4). Comparison with DMU 21 is much more instructive than comparison with the average of all farms in the study because DMU 21 has been determined to be efficient. In addition, DMU 5 was more comparable in input and output to DMU 21 than to the other efficient DMU.

The DEA results indicate that efficiency was attained by herds with the lowest input costs (such as DMU 21, 7, and 41), but herds with higher input costs also attained efficiency if they had low AFC or high milk production of heifers compared with the other cows in the herd (such as DMU 10, 30, and 32). For the $7 \mathrm{DMU}$ with the lowest efficiency scores, the changes recommended by the model, for all but DMU 
Table 3. Model inputs for data envelopment analysis of production efficiency of heifer rearing on 44 Pennsylvania farms

\begin{tabular}{|c|c|c|c|c|}
\hline \multirow[b]{2}{*}{$\mathrm{DMU}^{1}$} & \multicolumn{2}{|c|}{ Actual input } & \multicolumn{2}{|c|}{ Actual output ${ }^{2}$} \\
\hline & Feed, $\$ /$ head & Labor, \$/head & $\mathrm{AFC}, \mathrm{mo}$. & Relative milk, \% \\
\hline 1 & $1,016.93$ & 104.93 & 23.7 & 85.49 \\
\hline 2 & $1,304.90$ & 205.00 & 23.8 & 80.66 \\
\hline 3 & $1,122.83$ & 202.09 & 23.3 & 72.51 \\
\hline 4 & $1,507.11$ & 74.19 & 22.5 & 83.31 \\
\hline 5 & $1,091.56$ & 275.96 & 25.1 & 82.75 \\
\hline 6 & $1,415.13$ & 149.40 & 25.2 & 88.24 \\
\hline 7 & 849.76 & 120.41 & 23.8 & 82.88 \\
\hline 8 & 984.96 & 178.24 & 27.6 & 84.44 \\
\hline 9 & $1,727.10$ & 249.58 & 25.3 & 89.96 \\
\hline 10 & $1,230.77$ & 317.62 & 23.9 & 94.56 \\
\hline 11 & $1,136.45$ & 79.10 & 23.3 & 79.65 \\
\hline 12 & $1,707.91$ & 332.67 & 25.3 & 84.11 \\
\hline 13 & $1,184.87$ & 278.35 & 24.5 & 87.12 \\
\hline 14 & $1,431.04$ & 184.50 & 26.4 & 75.60 \\
\hline 15 & $1,459.83$ & 238.55 & 26.9 & 81.47 \\
\hline 16 & $1,871.39$ & 262.16 & 29.0 & 84.99 \\
\hline 17 & $1,156.39$ & 281.01 & 24.4 & 84.64 \\
\hline 18 & $1,979.85$ & 182.89 & 24.1 & 82.41 \\
\hline 19 & $1,463.70$ & 118.62 & 24.4 & 84.98 \\
\hline 20 & $1,819.95$ & 274.11 & 25.7 & 73.23 \\
\hline 21 & 819.12 & 124.95 & 25.0 & 87.95 \\
\hline 22 & $1,107.16$ & 125.68 & 29.0 & 83.18 \\
\hline 23 & $1,520.54$ & 220.72 & 25.3 & 79.69 \\
\hline 24 & $1,443.69$ & 361.46 & 25.5 & 76.35 \\
\hline 25 & $1,514.50$ & 149.36 & 25.0 & 82.30 \\
\hline 26 & $1,453.60$ & 132.78 & 24.7 & 82.82 \\
\hline 27 & $1,491.36$ & 104.38 & 22.8 & 88.44 \\
\hline 28 & $1,644.37$ & 251.76 & 27.6 & 77.58 \\
\hline 29 & $1,280.32$ & 262.11 & 24.0 & 91.52 \\
\hline 30 & $1,608.63$ & 88.20 & 24.5 & 92.14 \\
\hline 31 & $1,282.42$ & 393.98 & 25.2 & 79.50 \\
\hline 32 & $1,574.30$ & 82.47 & 22.2 & 83.02 \\
\hline 33 & $1,179.01$ & 66.25 & 22.5 & 87.97 \\
\hline 34 & $1,042.10$ & 138.13 & 23.0 & 85.99 \\
\hline 35 & $1,359.04$ & 143.89 & 28.3 & 80.02 \\
\hline 36 & $1,226.55$ & 435.98 & 26.5 & 87.30 \\
\hline 37 & $1,180.55$ & 243.07 & 26.7 & 66.58 \\
\hline 38 & $1,020.01$ & 210.56 & 25.0 & 99.32 \\
\hline 39 & $1,093.57$ & 258.17 & 25.9 & 80.76 \\
\hline 40 & $1,007.51$ & 129.17 & 23.8 & 69.53 \\
\hline 41 & 912.87 & 116.97 & 23.5 & 81.93 \\
\hline 42 & 999.18 & 154.49 & 24.2 & 85.58 \\
\hline 43 & $1,208.88$ & 245.92 & 23.3 & 86.45 \\
\hline 44 & $1,554.04$ & 360.57 & 27.5 & 87.16 \\
\hline
\end{tabular}

${ }^{1}$ Decision-making units (i.e., farms).

${ }^{2} \mathrm{AFC}=$ age at first calving, back-transformed to show the actual, collected values rather than the $(30-\mathrm{AFC})$ values that were used in the analysis; relative milk $=$ projected 305 - $\mathrm{d}$ actual milk production of first-lactation heifers as a percentage of projected 305-d actual milk of all other cows in the herd.

12, were to reduce AFC and improve milk production of heifers, even though these were the herds with the highest input costs. It is interesting to note that operations identified as efficient in this analysis do provide similar benchmarks as those that are commonly recommended in terms of output. Age at first calving for efficient farms ranged between 22.2 and 25.0 mo, and milk production relative to the rest of the herd ranged from 81.93 to $99.32 \%$. Goals promulgated for these measures are 23 to 24 mo AFC (Heinrichs, 1993) and 75 to $80 \%$ for milk yield (Nordlund and Cook, 2004). Inefficient herds from this study averaged 25.3 mo AFC and milk production of heifers was $82 \%$ of that of older cows in the herd. In this study, 305-d projected actual milk production on efficient farms ranged from $7,476 \mathrm{~kg}$ for first-lactation heifers and $8,500 \mathrm{~kg}$ for older cows (relative milk value of $88 \%$ ) to $10,821 \mathrm{~kg}$ for heifers and $12,584 \mathrm{~kg}$ for older cows (relative milk value of $86 \%$ ). When comparing these results for efficient herds with standard benchmarks, 
Table 4. Results of efficiency analysis of heifer rearing with decision-making units (DMU; i.e., farms) ranked by data envelopment analysis (DEA) efficiency score

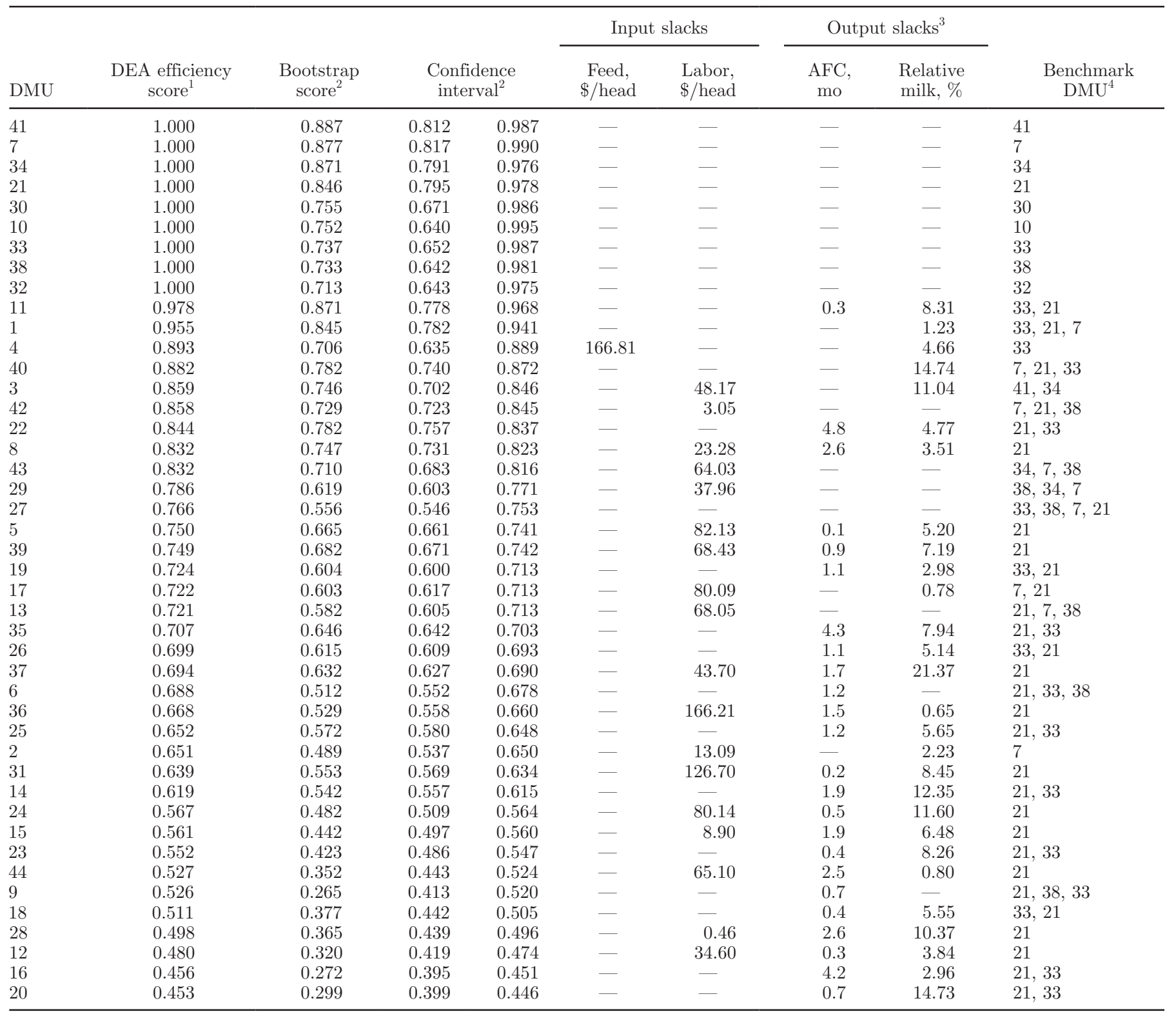

${ }^{1}$ Efficiency score determined from the BCC input-oriented model (Banker et al., 1984).

${ }^{2}$ Efficiency score and confidence interval at $\alpha=0.05$; determined using benchmarking package in R (Bogetoft and Otto, 2013).

${ }^{3} \mathrm{AFC}=$ age at first calving; relative milk = projected 305-d actual milk production of first-lactation heifers as a percentage of projected 305- $\mathrm{d}$ actual milk of all other cows in the herd.

${ }^{4}$ If more than one benchmark DMU is listed, they are in descending order of the weight assigned by the DEA model.

it is important to keep in mind that the measure of relative milk used in this study did not penalize a herd with cows milking below their potential. For example, DMU 38 was identified as efficient in heifer rearing, but the relative milk value of $99 \%$ suggests that older cows in this herd are likely not milking at their full potential, which may make heifer performance look better than it truly is.

\section{CONCLUSIONS}

The cost to raise heifers has increased significantly in the past $10 \mathrm{yr}$ and averaged $\$ 1,808$ from birth to calving, with feed representing $73 \%$ of total costs in this study. Data envelopment analysis determined that 9 of 44 farms had no inefficiencies in input or output. These farms best combined feed and labor investments, 
spending, on average, $\$ 1,137.40$ and $\$ 140.62 /$ heifer for feed and labor on heifers that calved at 23.7 mo of age and produced $88.42 \%$ of the milk produced by older cows. Efficiency was attained by herds with the lowest input costs, but herds with higher input costs could also be efficient if age at calving was low and milk production was high for heifers compared with the rest of the herd.

\section{ACKNOWLEDGMENTS}

Appreciation is extended to cooperating dairy farmers and to C. Williams, G. Hennip, G. Schurman, and G. Sheppard, Penn State extension educators who assisted with data collection. This research was funded by USDA grant no. 2010-34437-20803.

\section{REFERENCES}

Banker, R. D., A. Charnes, and W. W. Cooper. 1984. Some models for estimating technical and scale inefficiencies in data envelopment analysis. Manage. Sci. 3:1078-1092.

Bogetoft, P., and L. Otto. 2013. Benchmarking with DEA and SFA. $\mathrm{R}$ package version 0.23. R Foundation for Statistical Computing, Vienna, Austria.

Cooper, W. W., L. M. Seiford, and K. Tone. 2000. Data envelopment analysis: A comprehensive text with models, applications, references and DEA-Solver software. Kluwer Academic Publishers, Boston, MA.

Gabler, M. T., P. R. Tozer, and A. J. Heinrichs. 2000. Development of a cost analysis spreadsheet for calculating the costs to raise a replacement dairy heifer. J. Dairy Sci. 83:1104-1109.

Gabler, M. T., P. R. Tozer, A. J. Heinrichs, and T. Beck. 2007. Cost of raising replacement dairy heifers spreadsheet. Accessed Sep. 15 2012. http://extension.psu.edu/animals/dairy/health/nutrition/ heifers/economics/costs-to-raise-replacement-heifers-spreadsheet/ view.

Harsh, S., C. Wolf, and E. Wittenberg. 2001. Profitability and production efficiency of livestock and crop enterprises on Michigan dairy operations: 1998 summary and analysis. Agric. Econ. Staff Paper No. 01-04. Michigan State Univ., East Lansing.

Heinrichs, A. J. 1993. Raising dairy replacement heifers to meet the needs of the 21st century. J. Dairy Sci. 76:3179-3187.

Heinrichs, A. J., G. W. Rogers, and J. B. Cooper. 1992. Predicting body weight and wither height in Holstein heifers using body measurements. J. Dairy Sci. 75:3576-3581.
Hoffman, P., M. Wildeck, L. Milligan, T. Anderson, Z. Miller, I. Possin, D. McCauley, S. Gunderson, J. Keuning, R. Knapp, B. Cropp, C. Duley, T. Planer, L. Wind-Norton, K. Pokorny, G. Blonde, R. Tigner, T. Cadwallader, R. Wernberg, J. Tetzlaff, T. Howard, D. Wiersma, and S. Benson. 1999. Economic cost and labor efficiencies associated with rearing dairy herd replacements on Wisconsin dairy farms. Computer Model: Intuitive Cost of Production Analysis (ICPA). Univ. Wisconsin Ext., Madison.

Ishler, V. A. 2011. Feed Price List. Accessed Oct. 15, 2011. http:// extension.psu.edu/animals/dairy/business-management/feedprice-list.

Karszes, J. 1994. Dairy Replacement Programs: Costs and Analysis Western New York, 1993. Ext. Bull. 94-8, No. 174. Dept. Anim. Sci. and Dept. Agric. Resource, and Managerial Econ., Cornell Univ., Ithaca, NY.

Nordlund, K. V., and N. B. Cook. 2004. Using herd records to monitor transition cow survival, productivity, and health. Vet. Clin. North Am. Food Anim. Pract. 20:627-649.

NRC. 2001. Nutrient Requirements of Dairy Cattle. 7th rev. ed. Natl. Acad. Press, Washington, DC.

R Development Core Team. 2013. R: A Language and Environment for Statistical Computing. $\mathrm{R}$ version 3.0.0. $\mathrm{R}$ Foundation for Statistical Computing, Vienna, Austria.

Simar, L., and W. P. Wilson. 1998. Sensitivity analysis of efficiency scores: How to bootstrap in nonparametric frontier models. Manage. Sci. 44:49-61.

Stokes, J. R., P. R. Tozer, and J. Hyde. 2007. Identifying efficient dairy producers using data envelopment analysis. J. Dairy Sci. 90:2555-2562.

Tozer, P. R., and A. J. Heinrichs. 2001. What affects the costs of raising replacement dairy heifers: A multiple-component analysis. J. Dairy Sci. 84:1836-1844.

USDA. 2007. Dairy 2007, Part I: Reference of dairy cattle health and management practices in the US. USDA:APHIS:VS, NAHMS, Fort Collins, CO.

USDA. 2011a. Annual prices received. Accessed Jun. 1, 2012. http:// www.nass.usda.gov/Quick_Stats/.

USDA. 2011b. Farm labor. Accessed Nov. 17, 2011. http://usda01. library.cornell.edu/usda/nass/FarmLabo//2010s/2011/Farm Labo-11-17-2011.pdf.

USDA. 2012. Annual statistical bulletin. Accessed Feb. 22, 2012 http://www.nass.usda.gov/Statistics_by_State/Pennsylvania/ Publications/Annual_Statistical_Bulletin/2011_2012/index.asp.

Zanton, G. I., and A. J. Heinrichs. 2005. Meta-analysis to assess effect of prepubertal average daily gain of Holstein heifers on firstlactation production. J. Dairy Sci. 88:3860-3867.

Zwald, A., T. L. Kohlman, S. L. Gunderson, P. C. Hoffman, and T. Kriegl. 2007. Economic costs and labor efficiencies associated with raising dairy herd replacements on Wisconsin dairy farms and custom heifer raising operations. Univ. Wisconsin Ext., Madison. 